\title{
TRABALHO ESCRAVO - O COMBATE EM XEQUE: UMA ANÁLISE CRÍTICA SOBRE AS TENTATIVAS DE ALTERAÇÃO DO CONCEITO E SEUS DESDOBRAMENTOS
}

\author{
Robson Heleno da Silva ${ }^{1}$ \\ Valena Jacob ${ }^{2}$
}

\section{RESUMO}

O trabalho visa a analisar os principais projetos de lei em trâmite no Congresso Nacional que contém previsões que afetam diretamente ou indiretamente a política estatal de erradicação do crime de redução a condição análoga à de escravo no Brasil. Através da apreciação das justificativas apresentadas para tais projetos, buscar-se-á identificar os argumentos utilizados como fundamento, confrontando-os ao entendimento doutrinário e jurisprudencial. Demonstrar-se-á que os argumentos não prosperam diante do que é defendido atualmente, tanto pela doutrina quanto pela jurisprudência, ficando evidente que a aprovação dos mesmos implicará em grave retrocesso e enfraquecimento direto no combate ao crime em questão.

Palavras-chave: Projetos - lei - trabalho - escravo - combate.

\section{SLAVE LABOR - THE COMBAT IN CHECK: A CRITICAL ANALYSIS OF ATTEMPTS TO CHANGE THE CONCEPT AND ITS UNFOLDINGS}

\begin{abstract}
The work analyze the main bills in progress at the National Congress which contains forecasts that, directly or indirectly, affect the state's policy of eradicating the crime of reducing the condition analogous to slavery in Brazil. By the assessment of the justifications presented, it'll be sought to identify the arguments used as a basis, confronting them with the doctrinal and jurisprudential understanding. It'll be demonstrated that the arguments don't thrive against of what's now being defended at the doctrine and jurisprudence, evident, thus, their approval will lead to serious setbacks and direct weakening of the crime in question.
\end{abstract}

Keywords: Bills - Eradicating - Crime - Analogous - Slavery - Setbacks

\section{INTRODUÇÃO}

Embora inexista no ordenamento jurídico brasileiro desde 1888, ocasião em que fora formalmente abolido pela Lei Áurea (Lei $\mathrm{n}^{\circ} 3.353 / 1888$ ), o trabalho escravo é mácula que persiste até os presentes dias. O trabalho em condições análogas às de escravo, como é denominado atualmente, apesar de ser caracterizado pelo recurso a meios distintos daqueles observados há alguns séculos, também pode ser simplesmente denominado de "trabalho escravo".

\footnotetext{
${ }^{1}$ Advogado. Voluntário da Clínica de Direitos Humanos da Amazônia. Mestrando em Direito pelo Programa de Pós-Graduação em Direito da UFPA. Bolsista financiado pela Capes. E-mail: robson-hs@ hotmail.com.

2 Doutora e Mestre em Direito pela UFPA. Professora da Graduação em Direito e do Programa de Pós Graduação em Direitos Humanos da UFPA; Diretora da Faculdade de Direito da UFPA e Pesquisadora da Clínica de Direitos Humanos da Amazônia/UFPA. e-mail: valena_jacob@yahoo.com.br
} 
Neste sentido, aduz Brito Filho (2014, p. 30):

É preciso ter em mente, entretanto, que esta é apenas uma forma reduzida da expressão mais ampla e utilizada pela lei. Pois, não sendo a escravidão, como dito, prática admitida pelo ordenamento jurídico, não se pode admitir que a pessoa humana, mesmo em razão de conduta ilícita de outrem, possa vir a ser escrava; no máximo, ela estará em condição análoga à de escravo.

O trabalho escravo contemporâneo atenta não só contra a liberdade do indivíduo, mas, sobretudo, contra a sua dignidade ${ }^{3}$. Brito Filho (2010, p. 66) defende que trata-se de:

[...] uma violação direta ao principal atributo do ser humano, que é sua dignidade, pois qualquer das condutas descritas no artigo 149 é a negação desse atributo, reduzindo a pessoa à condição de coisa. Isso vai acontecer tanto quando ao ser humano é imposto o trabalho forçado ou uma jornada exaustiva de trabalho, como quando lhe são reservadas condições degradantes de trabalho, ou ainda nas demais hipóteses catalogadas no artigo, como no caso da restrição à locomoção por dívida contraída.

Os modos de execução evoluíram ao longo do tempo, porém, ainda se vislumbra a presença do uso da coação (física ou moral), bem como do abuso do poder econômico. $\mathrm{O}$ escravocrata contemporâneo, na maioria das vezes, atua por meio de intermediários, responsáveis por aliciar, contratar e gerenciar os trabalhadores, que são facilmente atraídos por promessas fraudulentas.

Acerca destes intermediários, esclarece Lívia Miraglia: (2015, p.136)

Há também a figura dos "gatos", pessoas que se dispõem a aliciar trabalhadores de regiões distantes - ludibriando-os com promessas faltas de boas condições de trabalho e remuneração -, e a leva-los ao local onde o serviço será prestado. Na maioria das vezes, os obreiros são recrutados para trabalhar em fazendas, madeireiras ou carvoarias situadas em regiões isoladas e distantes, o que dificulta a fuga e facilita a submissão, pois o trabalhador sequer sabe onde está.

Seja no meio rural, na agricultura e pecuária, ou no urbano, na construção civil e indústria têxtil, a exploração da mão-de-obra escrava tem ocorrido em todo o Brasil através dos anos. Segundo dados do Ministério do Trabalho ${ }^{4}$, de 1995 a 2015, um total de 49.816 (quarenta e nove mil, oitocentas e dezesseis) pessoas foram libertadas da escravidão, sendo 12.799 (doze mil setecentos e noventa e nove) delas somente no estado do Pará, que é o estado onde se concentram os maiores casos de escravidão contemporânea rural.

Diante deste panorama, o Estado brasileiro tem se empenhado através dos anos em fortalecer os mecanismos de combate a este problema, que afeta não só as vítimas, violando seus direitos fundamentais e ferindo sua dignidade, mas a sociedade como um todo.

Neste sentido, destaca-se o voto do então Ministro Joaquim Barbosa que, em relatoria no $\mathrm{RE} \mathrm{n}^{\circ}$ 398.041/PA, de 2006, afirmou:

Com isso quero dizer que quaisquer condutas que possam ser tidas como violadoras não somente do sistema de órgãos e instituições com atribuições

\footnotetext{
${ }^{4}$ Dados organizados pelo Ministério do Trabalho e Previdência Social a partir de fiscalizações de trabalho escravo realizadas de maneira conjunta por Ministério do Trabalho, Ministério Público do Trabalho, Polícia Federal e Polícia Rodoviária Federal desde 1995. Disponível em:

<http://reporterbrasil.org.br/dados/trabalhoescravo/>. Acesso em 02 de novembro de 2016.
} 
para proteger os direitos e deveres dos trabalhadores, mas também do homem trabalhador, atingindo-o nas esferas que lhe são mais caras, em que a Constituição lhe confere proteção máxima, são, sim, enquadráveis na categoria dos crimes contra a organização do trabalho, se praticadas no contexto das relações de trabalho.

No entanto, paradoxalmente, o que se observa nos últimos anos é o fortalecimento de um discurso em prol da mitigação dos mecanismos de combate, seja por meio da redução no número de fiscalizações do Ministério do Trabalho e Emprego, seja através do surgimento de projetos de lei contendo previsões que, direta ou indiretamente, pretendem gerar um enfraquecimento no combate ao trabalho escravo.

O presente trabalho se propõe a analisar os principais projetos de lei que possuem previsões que, caso sejam convertidas em lei, representarão um grave retrocesso no âmbito da proteção às vítimas e ao combate ao crime em estudo. A metodologia utilizada será a pesquisa bibliográfica.

\section{EVOLUÇÃO DOS MECANISMOS DE COMBATE}

Antes de tratar dos projetos de lei propriamente, cumpre fazer um breve apanhado histórico da evolução dos mecanismos de combate ao trabalho escravo, destacando as medidas adotadas pelo Brasil através dos anos. Tal se faz necessário, para que se possa compreender em que medida os projetos de lei podem ser danosos.

Primeiramente, destacam-se as medidas adotadas no âmbito internacional. Em ordem cronológica, houve a vinculação do Estado brasileiro aos seguintes instrumentos de proteção aos direitos humanos: Convenção contra a Escravidão, de 1926; Declaração Universal dos Direitos Humanos, de 1948; Convenção Suplementar sobre a abolição da escravatura, de 1956; Pacto Internacional de Direitos Civis e Políticos de 1966; Convenção Americana de Direitos Humanos da Organização dos Estados Americanos, de 1969.

Ressalta-se ainda a vinculação às Convenções da Organização Internacional do Trabalho, quais sejam a $\mathrm{n}^{\mathrm{o}} 29$ (Convenção Sobre o Trabalho Forçado ou Obrigatório) e a $\mathrm{n}^{\circ}$ 105 (Convenção Relativa a abolição do Trabalho Forçado), as quais foram promulgadas no ordenamento jurídico brasileiro por meio dos Decretos $n^{\circ}$ 41.721/1957 e 58.882/1966, respectivamente.

No plano interno, a Constituição Federal de 1988 trouxe em seu bojo diversas previsões assecuratórias da proteção e garantia dos direitos individuais, sobretudo no que diz respeito ao trabalho digno, à vedação ao trabalho forçado e ao tratamento desumano e degradante. Entretanto, a exploração de trabalho escravo persistiu no país, havendo o reconhecimento da existência do problema em 1995, após denúncia formulada perante a Organização dos Estados Americanos.

No âmbito político, foram adotadas diversas medidas, dentre as quais merecem destaque: o lançamento do Primeiro Plano Nacional para a Erradicação do Trabalho Escravo, em 2003; a criação da Comissão Nacional de Erradicação do Trabalho Escravo (CONATRAE), também em 2003; a criação do Cadastro de Empregadores Infratores, por meio da portaria $n^{\circ} 540$ do Ministério do Trabalho e Emprego, em 2004; o lançamento do Segundo Plano Nacional para a Erradicação do Trabalho Escravo, elaborado pela CONATRAE, em 2008. 
Porém, o principal passo foi dado em 2003, no plano legislativo. Neste ano, foi aprovada a lei $\mathrm{n}^{\mathrm{o}} 10.803 / 2003$, que alterou o artigo 149, do Código Penal Brasileiro, tipificando o crime de "redução a condição análoga à de escravo", descrevendo condutas típicas, bem como modalidades equipadas ao tipo penal, conforme se observa no texto do dispositivo:

Art. 149. Reduzir alguém a condição análoga à de escravo, quer submetendo-o a trabalhos forçados ou a jornada exaustiva, quer sujeitando-o a condições degradantes de trabalho, quer restringindo, por qualquer meio, sua locomoção em razão de dívida contraída com o empregador ou preposto: Pena - reclusão, de dois a oito anos, e multa, além da pena correspondente à violência.

$\S 1$ o Nas mesmas penas incorre quem:

I - cerceia o uso de qualquer meio de transporte por parte do trabalhador, com o fim de retê-lo no local de trabalho;

II - mantém vigilância ostensiva no local de trabalho ou se apodera de documentos ou objetos pessoais do trabalhador, com o fim de retê-lo no local de trabalho.

Acerca do supracitado crime, acrescenta Valena Jacob (2016, p. 41):

Ressalta-se, inicialmente, que para a configuração do tipo penal em questão, basta a constatação, no caso concreto, de apenas uma das condutas típicas ou equiparadas, apesar de que na maioria das vezes, quase todas as condutas são percebidas pela fiscalização do Ministério do Trabalho e Emprego de forma conjunta, refletindo a lógica da superexploração do trabalhador no cenário laboral brasileiro.

Conforme se observa, o Código Penal prevê um conceito amplo, que visa à proteção da dignidade da pessoa humana, já que o crime em comento é uma violação direta ao principal atributo do ser humano, que é sua dignidade, pois qualquer das condutas descritas no artigo 149 é a negação desse atributo, reduzindo a pessoa à condição de coisa. (BRITO FILHO, 2010, p. 66)

Conclui-se assim que a lei objetiva englobar as diversas situações que há muito já eram encontradas nas fiscalizações trabalhistas do Ministério do Trabalho e Emprego. A despeito de sua importância e amplitude, atualmente este conceito está sendo alvo de projeto de lei que tende a restringi-lo, conforme será exposto no próximo tópico.

Mais recentemente, em 2014, houve a edição da Emenda Constitucional n ${ }^{\circ}$ 81, a qual alterou o artigo 243 da Constituição Federal, criando a possibilidade de expropriação das terras onde haja a exploração de trabalho escravo, senão vejamos in verbis:

Art. 243. As propriedades rurais e urbanas de qualquer região do País onde forem localizadas culturas ilegais de plantas psicotrópicas ou a exploração de trabalho escravo na forma da lei serão expropriadas e destinadas à reforma agrária e a programas de habitação popular, sem qualquer indenização ao proprietário e sem prejuízo de outras sanções previstas em lei, observado, no que couber, o disposto no art. $5^{\circ}$.

Parágrafo único. Todo e qualquer bem de valor econômico apreendido em decorrência do tráfico ilícito de entorpecentes e drogas afins e da exploração 
de trabalho escravo será confiscado e reverterá a fundo especial com destinação específica, na forma da lei.

Conquanto não se possa ignorar sua importância, é preciso destacar que o projeto de lei que visa a regulamentar sua aplicação pretende adotar um conceito diferente do previsto atualmente no código penal, mais restrito, conforme se estudará adiante.

\section{O PROJETO DE LEI No 3.842/2012}

De autoria do Deputado Moreira Mendes, do PSD de Rondônia, o referido Projeto de Lei foi apresentado em 09/05/2012, perante a Câmara dos Deputados, trazendo em seu texto proposta de modificação do artigo 149, do Código Penal, a fim de suprimir do caput do o referido dispositivo, as modalidades típicas "jornada exaustiva" e "condições degradantes de trabalho".

De acordo com a justificativa apresentada pelo projeto, a referida modificação se fundamenta no argumento de que a tipificação do crime é inadequada, na medida em que não há uma definição objetiva do que seria uma "jornada exaustiva" ou "condições degradantes de trabalho", prejudicando assim, a atuação dos órgãos de fiscalização e repressão do Estado.

Não obstante, a existência de tais "elementos de indeterminação" supostamente traz insegurança jurídica, visto que deixa ampla margem para interpretações subjetivas, facilmente questionadas no processo judicial. A subjetividade que circunda tais modalidades, portanto, seria responsável pelo baixo índice de condenações pela justiça brasileira, gerando apenas impunidade aos infratores.

Embora o referido projeto de lei esteja, atualmente, em trâmite perante a Mesa Diretora da Câmara dos Deputados, tendo sua última movimentação ocorrida em 11/08/2015, é preciso destacar que o mesmo foi apresentado com regime de tramitação prioritário, conforme prevê o artigo 151, II, do Regimento Interno da Câmara dos Deputados.

\subsection{Elementos de indeterminação}

Averiguando a justificativa apresentada é possível destacar que a mesma não se sustenta, se analisada à luz de estudos recentes. O argumento baseado na ausência de definição objetiva sobre as duas modalidades que se pretende suprimir, não procede, haja vista que a doutrina possui conceitos definidos acerca de ambas as hipóteses.

Acerca da "jornada exaustiva”, em publicações anteriores assevera Valena Jacob (2016, p. 57):

Desta feita, a jornada exaustiva, como o próprio nome denota, também é comumente caracterizada pela imposição sistemática por parte do empregador de demasiado esforço físico ao trabalhador, com considerada sobrecarga de trabalho e exigência de produtividade mínima, como forma de possibilitar melhora na remuneração ou manutenção do emprego, deixando de proporcionar tempo suficiente para a recuperação física do obreiro, acarretando assim risco para sua vida e saúde.

Não obstante, a doutrina penal de Guilherme de Souza Nucci (2008, p. 691) a caracteriza como sendo: 
[...] o período de trabalho diário que foge às regras da legislação trabalhista, exaurindo o trabalhador, independentemente de pagamento de horas extras ou qualquer outro tipo de compensação. [...]. Para a configuração do crime do art. 149 é preciso que o patrão submeta (isto é, exija, subjugue, domine pela força) o seu empregado a tal situação

Não obstante, é preciso ressaltar que há ainda a jornada exaustiva decorrente da intensidade do trabalho, sendo aquela em que os limites da capacidade física do trabalhador são extrapolados. Portanto, ainda que a jornada de trabalho não extrapole o máximo permitido pela Constituição Federal e normas trabalhistas, se for realizada de modo extenuante, poderá ser caracterizada como exaustiva, podendo tipificar o crime do artigo 149 do CP.

No que tange o trabalho em condições degradantes, Nucci aduz que é aquele onde o trabalhador se vê submetido a condições de trabalho indignas, incompatíveis com as normas trabalhistas, que asseguram as mínimas condições de segurança e salubridade. Nestas situações, embora o tipo penal seja aberto, dando margem à interpretação do magistrado, este deve valer-se do bom senso e da legislação trabalhista, quando da análise do caso concreto. (2008. p. 691)

Ademais, conclui Brito Filho que sempre que forem negadas ao trabalhador as condições básicas de trabalho, pondo em risco a sua segurança e oferecendo riscos à sua saúde, haverá trabalho em condições degradantes. Da mesma maneira, se a jornada de trabalho possui duração que compromete o descanso e priva o trabalhador do convívio social, ou se, para prestar o trabalho, há limitações na alimentação, higiene e moradia do trabalhador, restará caracterizado o trabalho em condições degradantes. (2010. P. 72)

Por fim, destaca-se, ainda, a seguinte decisão, onde o magistrado entendeu que as "condições degradantes de trabalho" restavam configuradas em virtude do desrespeito não apenas às normas trabalhistas, mas, sobretudo às condições de saúde, segurança, higiene, respeito e alimentação mínimas, que devem ser fornecidas ao trabalhador:

PENAL. CRIME CONTRA A LIBERDADE. REDUÇÃO À CONDIÇÃO ANÁLOGA A DE ESCRAVO (ART. 149, caput, DO CP). FATOS OCORRIDOS EM 2003. AUTORIA E MATERIALIDADE COMPROVADAS. 1. O tipo objetivo - sujeitar alguém à vontade do agente, escravizar a pessoa humana - descrito na antiga redação do art. 149 do Código Penal, depois da publicação da Lei 10.803, de 11.12.2003, continuou o mesmo. A nova Lei 10.803/03 apenas explicitou as hipóteses em que se configuram a condição análoga à de escravo, como, por exemplo, a submissão a trabalhos forçados, a jornada exaustiva, o trabalho em condições degradantes, a restrição da locomoção em razão de dívida com o empregador ou preposto. A nova lei ainda acrescentou formas qualificadas, punindo o crime com o aumento da pena em metade. 2. Trabalhadores submetidos a condições de trabalho degradantes, num cenário humilhante de trabalho, indigno de um humano livre, havendo não apenas desrespeito a normas de proteção do trabalho, mas desprezo a condições mínimas de saúde, segurança, higiene, respeito e alimentação, além de exercerem trabalho em servidão por contas de dívidas ali contraídas, pois se verifica que eram vendidos aos trabalhares insumos básicos, como arroz e feijão e equipamentos de proteção individual, comprovam a autoria do crime previsto no art. $149, \S 2^{\circ}$, I, do CP pelo acusado. 3. Materialidade e autoria comprovadas pelos documentos acostados e provas testemunhais 
produzidas. 4. Aumento do concurso formal entre crimes da mesma espécie fixado em $1 / 2$ (metade), em virtude de 154 (cento e cinquenta e quatro) trabalhadores terem sido reduzidos à condição análoga à de escravo. 5 . Recurso provido. (TRF-1 - ACR: 616 PA 0000616-97.2007.4.01.3901, Relator: DESEMBARGADOR FEDERAL TOURINHO NETO, Data de Julgamento: 17/12/2012, TERCEIRA TURMA, Data de Publicação: e-DJF1 p.769 de 11/01/2013, grifo nosso)

Desta feita, fica evidente que o argumento baseado na "ausência de definição" para os modos de execução "jornada exaustiva" e "trabalho degradante" não pode prevalecer, vez que ambos são devidamente conceituados, tanto pela doutrina penal, quanto pela doutrina específica acerca da temática do "trabalho escravo contemporâneo".

\section{2 - O baixo índice de condenações}

No que tange ao argumento que associa as duas modalidades ao baixo índice de condenações, que geraria a impunidade é possível destacar recente estudo de análise jurisprudencial, realizado pela Clínica de Direitos Humanos da Amazônia ${ }^{5}$, vinculada à Universidade Federal do Pará, onde se identificou que o baixo índice de condenações está ligado a fatores como a ausência de provas, e entendimentos retrógrados de alguns magistrados, que entendem que o bem jurídico tutelado pelo crime é apenas a liberdade individual, bem como que as violações se tratam de meras irregularidades trabalhistas. Nenhum dos argumentos estava relacionado à inadequação do tipo penal.

Cabe aqui, portanto, a crítica acerca do referido Projeto, que se presta unicamente aos interesses políticos de uma Bancada Ruralista que tem ganhado força no Congresso Nacional nos últimos anos. Tal pode ser constatado facilmente, na medida em que se observa que o autor do Projeto é membro da referida bancada e, conforme sua biografia disponível na página da Câmara dos Deputados tem a pecuária como uma de suas profissões. Ou seja, há claramente uma busca em favorecer aos seus próprios interesses, em detrimento das vítimas e do combate a um problema que assola o país há séculos.

\section{4 - O PROJETO DE LEI DO SENADO n 432/2013}

Em 2014, foi aprovada a Emenda Constitucional n 81, a qual alterou a redação do artigo 243, da Constituição Federal, criando a possibilidade de expropriação de propriedades urbanas e rurais onde houver a exploração de trabalho escravo. Embora tenha sido um importante passo na repressão do crime, a nova redação prevê a necessidade de lei regulamentadora. Ademais, adotou terminologia diversa da utilizada no Código Penal, deixando em aberto a possibilidade de que uma conceituação diversa seja adotada.

Em 18 de outubro de 2013, aproximadamente um ano antes da aprovação da EC n ${ }^{\circ}$ 81, foi protocolado o Projeto de Lei do Senado ${ }^{\circ} 432$. De autoria do Senador Romero Jucá, o referido PLS dispõe sobre expropriação das propriedades rurais e urbanas onde se localizem a exploração de trabalho escravo e dá outras providências. Prevê, portanto, o procedimento a ser adotado quando da expropriação, bem como estabelece um conceito de "trabalho escravo", para fins de aplicação do artigo 243, da Constituição Federal.

\footnotetext{
${ }^{5}$ Projeto de Pesquisa PIBIC/PRODOUTOR, intitulado “O TRABALHO ANÁLOGO AO DE ESCRAVO: uma análise jurisprudencial sobre a caracterização do crime no Judiciário Federal Brasileiro"
} 
Em seu texto original, o PLS 432 prevê um conceito para "trabalho escravo", no §1", do seu artigo $1^{\circ}$, conforme transcrição a seguir:
Art. $1^{\circ}$. [...] $\S 1^{\circ}$ Para fins desta Lei, considera-se trabalho escravo:
I - a submissão a trabalho forçado, exigido sob ameaça de punição, com uso de coação, ou que se conclui da maneira involuntária, ou com restrição da liberdade pessoal;
II - o cerceamento do uso de qualquer meio de transporte por parte do trabalhador, com o fim de retê-lo no local de trabalho;
III - a manutenção de vigilância ostensiva no local de trabalho ou a apropriação de documentos ou objetos pessoais do trabalhador, com o fim de retê-lo no local de trabalho; e
IV - a restrição, por qualquer meio, da locomoção do trabalhador em razão de dívida contraída com empregador ou preposto.

Observa-se, portanto, que há a pretensão de adotar um conceito diverso do previsto no artigo 149 do Código Penal, que trata da redução a condição análoga à de escravo, visto que não enquadra todas as modalidades previstas por este. $\mathrm{O}$ conceito proposto é mais restrito, não contemplando as modalidades "jornada exaustiva" e "condições degradantes de trabalho".

Na justificação do referido PLS, argumenta-se acerca da necessidade de estabelecer um conceito sobre "trabalho escravo" para fins de expropriação, sob a alegação de que existe ainda muita incerteza e subjetivismo no conceito previsto no art. 149 do $\mathrm{CP}$, não existindo na doutrina ou jurisprudência uma definição cabal. Ressalta ainda que o fato principal para definir o trabalho escravo é o tolhimento da liberdade, com o fim de exploração do trabalho, considerando a liberdade individual o principal bem jurídico tutelado.

Em última movimentação realizada no dia 04/04/2017, o projeto foi remetido ao Plenário do Senado Federal e aguarda inclusão na ordem do dia, conforme requerimento de seu autor. Cumpre destacar que o mesmo já foi alvo de diversas emendas, porém, dentre as aprovadas, nenhuma versava sobre o conceito de "trabalho escravo". Ademais, em fevereiro de 2016, o mesmo foi incluído na pauta de urgência para ser votado, no entanto, retirado logo em seguida.

\section{1 - Incerteza e subjetivismo}

No que diz respeito ao argumento que alega a incerteza e subjetivismo que envolve o conceito de "trabalho em condições análogas à de escravo", se faz necessário destacar que o mesmo não prospera. Isto é corroborado na medida em que o PLS 432/2013, ao conceituar o "trabalho escravo", traz previsão similar à do artigo 149, do Código Penal, ficando visível o influxo deste diploma, vez que grande parte das modalidades tipificadas são replicadas na definição do PLS.

É possível que se defenda que a referida justificativa se volta, portanto, à exclusão das modalidades "jornada exaustiva" e "trabalho em condições degradantes". Neste caso, cumpre fazer menção à argumentação desenvolvida no tópico II.1 deste trabalho, onde já enfrentamos argumentos similares, restando esclarecido que tanto a doutrina quanto a jurisprudência já possuem definições sobre as referidas modalidades.

Por fim, cumpre destacar que o "trabalho escravo", conforme descrito na introdução deste trabalho, foi abolido do ordenamento jurídico brasileiro em 1988, com a edição da Lei 
Áurea. O trabalho escravo possui como característica primordial a existência de um direito de propriedade de um indivíduo (escravocrata) sobre o outro (escravo). Portanto, o que existe nos dias atuais é um trabalho explorado em condições análogas às da escravidão, dado que não há um direito de propriedade subjacente à relação, mas sim a violação de direitos trabalhistas e fundamentais.

\section{2 - A liberdade como elemento definidor}

$\mathrm{O}$ argumento que a restrição da liberdade deve ser considerada como elemento definidor do "trabalho escravo", sendo a liberdade individual o principal bem jurídico tutelado, tem por base o equívoco comum de querer analisar a exploração de mão-de-obra escrava nos dias atuais, como se a mesma ainda se desenvolvesse nos moldes do período colonial.

Conquanto se trate de visão já rechaçada pela doutrina, persiste o entendimento de que o bem jurídico tutelado no crime do artigo 149, do Código Penal, é a liberdade individual. Em pesquisa recente de análise jurisprudencial, realizada pela Clínica de Direitos Humanos da Amazônia, identificou-se que boa parte das sentenças absolutórias em primeira instância são fundamentadas em argumentos que consideram a "liberdade individual" como principal bem jurídico tutelado.

A título de exemplo, é possível destacar a seguinte sentença proferida nos autos do processo $\mathrm{n}^{\circ}$ 0000703-30.2013.4.01.3000, na Sessão Judiciária do Acre, e que, inclusive, contou com o aval do Ministério Público Federal, que em sede de alegações finais, também argumentou com base na ausência de violação à liberdade individual:

A conduta imputada ao réu está tipificada em capítulo do Código Penal cujo bem jurídico protegido é a liberdade individual. Ainda que existentes condições não adequadas de trabalho, não pode o Juiz fechar os olhos para aquilo que o Procurador da República já referiu: o Estado do Acre tem colonização nova, o que praticamente acarreta a inexistência de fazendas nos moldes coloniais. Digo, de propriedades onde há divisão entre sede, curral, casas de colonos, etc.

Em monografia ${ }^{6}$ elaborada por bolsista da Clínica de Direitos Humanos da Amazônia, voltada à análise da jurisprudência no âmbito do Supremo Tribunal Federal, acerca do crime do artigo 149, aduz-se que a visão que considera a "liberdade individual" como bem jurídico violado, prevaleceu durante muito tempo no âmbito da Suprema Corte. Porém, atualmente, tem prevalecido o entendimento de que o bem jurídico tutelado é a dignidade da pessoa humana, corroborando o que há anos é pregado pela doutrina.

Neste sentido, destaca-se a visão Ministra Ellen Gracie que, na relatoria do Acórdão sobre Inquérito 2.131/DF, 2012, afirmou que:

(...) a Lei $\mathrm{n}^{\circ}$ 10.803/2003 - alterou a redação do art. 149, do Código Penal, ao ampliar o rol de condutas amoldadas ao crime de redução a condição análoga à de escravo. Em ambos os tipos penais, na realidade, há claro

\footnotetext{
${ }^{6}$ Monografia intitulada "A visão do Supremo Tribunal Federal a respeito do crime de redução a condição análoga à de escravo", elaborada por Marília Roberta Maia da Silva, como Trabalho de Conclusão do Curso de Bacharelado em Direito pela Universidade Federal do Pará.
} 
atentado ao princípio da dignidade da pessoa humana na vertente do direito à liberdade e do direito ao trabalho digno.

Apesar disso, ainda há Ministros que insistem em defender a posição relativa à "liberdade individual", denotando não só uma tendência conservadora, mas principalmente uma falta de sensibilidade para com as vítimas. Tal é o caso do Ministro Gilmar Mendes que, ao votar no Acórdão supracitado, afirmou:

Friso, mais uma vez, que o bem jurídico pela norma não é a relação de trabalho, mas a liberdade individual. Não se trata de tipo penal com o objetivo de criminalizar infração de natureza trabalhista, muito menos de um delito que tenha por objeto jurídico o meio ambiente do trabalho. Insisto, cuida o art. 149 de tipificação que se insere entre aquelas que protegem liberdade individual de todo o cidadão.

Portanto, se tal argumento retrógrado e equivocado ainda encontra guarida no âmbito da Suprema Corte, não nos surpreende que o mesmo seja replicado por um Senador membro da Bancada Ruralista. Porém, isto não muda o fato de que resta evidente o interesse em adotar conceito mais restrito, seja para, com efeito direto, reduzir as possibilidades de expropriação de terras, seja para, de forma indireta, fortalecer o Projeto de Lei $n^{\circ} 3.842 / 2012$, analisado anteriormente, culminando na alteração da previsão do artigo 149, do Código Penal.

\section{5 - PROJETO DE LEI no 1.572/2011 (O NOVO CÓDIGO COMERCIAL)}

De autoria do Deputado Vicente Cândido, o Projeto de Lei ${ }^{\circ} 1.572 / 2011$ foi apresentado perante a Câmara dos Deputados em 16/06/2011, com o objetivo de instituir o Novo Código Comercial Brasileiro, que irá reger as relações jurídicas de empresas e empresários. A finalidade do referido código é substituir a aplicação Código Civil às relações empresariais, a fim de reduzir a burocracia e garantir a segurança jurídica.

Embora o texto original do projeto não apresente, em um primeiro momento, previsões que possam, ainda que indiretamente, atentar contra o combate ao trabalho escravo, merece destaque o substitutivo do texto original encaminhado em 13/07/2016 para a análise de Comissão Especial, contendo alterações promovidas por emendas cuja aprovação é recomendada em parecer de relatoria do Deputado Paes Landim.

Dentre as emendas aprovadas, está a Emenda Aditiva no 214/15, proposta pelo Deputado José Carlos Aleluia (DEM-BA), que trata especificamente do capítulo "Da proteção da empresa", dispondo acerca da fiscalização nas empresas. No substitutivo supracitado, as alterações da referida emenda se consubstanciam no acréscimo de um $\S 2^{\circ}$ ao artigo 75 , bem como na modificação da redação do artigo 76, e acréscimo de um parágrafo único a este dispositivo. A seguir, analisaremos as previsões da emenda isoladamente.

\section{1 - O fim da fiscalização conjunta}

Trataremos primeiramente em analisar o $\S 2^{\circ}$, do artigo 75 , in verbis:

Art. 75. $\S 2^{\circ}$ - Sempre que determinada autoridade estiver realizando fiscalização presencial em um estabelecimento empresarial, nenhuma outra 
autoridade de competência diversa pode realizar fiscalização simultânea no mesmo local, salvo se autorizada por juiz competente.

O referido dispositivo veda a realização de fiscalização simultânea por autoridades de competência diversa. As fiscalizações que resultam em resgates de trabalhadores submetidos à condição análoga à de escravo são realizadas pelos Grupos Especiais de Fiscalização Móvel (GEFM).

Criado pelo Ministério do Trabalho e Emprego (MTE) em 1995, geralmente, é composto por auditores-fiscais do trabalho, delegados e agentes da Polícia Federal, bem como procuradores do Ministério Público do Trabalho. Pode ainda ter a participação de membros da Procuradoria-Geral da República e de membros do Instituto Brasileiro do Meio Ambiente e dos Recursos Naturais Renováveis (IBAMA) e do Instituto Nacional de Colonização e Reforma Agrária (INCRA).

Logo, caso seja aprovada a previsão do $\S 2^{\circ}$, as fiscalizações do GEFM não poderão mais acontecer, já que compreendem a articulação de diversos órgãos e autoridades. Cumpre ainda ressaltar que, atualmente, o GEFM é um dos principais instrumentos do Estado para reprimir o trabalho escravo contemporâneo. Conforme dados do $\mathrm{MTE}^{7}$, entre 1995 e 2015, o GFEM realizou 2.020 operações, tendo inspecionado 4.303 estabelecimentos, e libertado 49.816 pessoas em situação análoga à escravidão.

Portanto, resta evidente que a aprovação do referido parágrafo representará um grande golpe ao combate ao trabalho escravo, visto que o principal instrumento de repressão à exploração será desmantelado.

\section{2 - A fiscalização programada}

Não obstante, há ainda a redação proposta ao artigo 76 e seu parágrafo único, que são igualmente danosas. Senão, vejamos:

Art. 76. A fiscalização presencial deve ser comunicada à empresa, pela autoridade administrativa, por intermédio de seu órgão fiscalizador, com antecedência mínima de 2 (dois) dias úteis.

Parágrafo único. Nos casos em que o aviso antecipado puder comprometer ou prejudicar a eficiência da ação fiscalizadora, o juiz competente, mediante provocação do respectivo órgão físcalizador, poderá dispensar-lhe da comunicação prevista no caput deste artigo.

Conforme o caput do dispositivo, as fiscalizações deverão ser comunicadas com antecedência. Ressalva-se, no entanto, em seu parágrafo único, a possibilidade de que a comunicação seja dispensada, caso haja a solicitação perante a justiça de autorização para que se proceda à fiscalização, na hipótese de que o aviso possa comprometer o andamento da ação.

Tendo em vista que as fiscalizações são realizadas sem qualquer aviso prévio, justamente para flagrar as condições reais em que o trabalho é desenvolvido, o referido dispositivo é também danoso ao combate ao trabalho escravo. A necessidade de aviso prévio

\footnotetext{
${ }^{7}$ Dados disponíveis em <http://reporterbrasil.org.br/dados/trabalhoescravo/>. Acesso em: 15.05.2017.
} 
desarticula a lógica da fiscalização, visto que, sabendo que serão fiscalizados, com dois dias de antecedência, os empresários terão tempo o bastante para dissimular todas as irregularidades que possuam, principalmente aqueles que exploram o trabalho escravo.

Embora haja a previsão de dispensa mediante autorização judicial, esta acaba por engessar a atuação dos grupos de fiscalização, já que ficarão dependentes da concessão de autorizações, o que afetará drasticamente o número de fiscalizações e, consequentemente, de resgates de trabalhadores.

\section{3 - Justificativa e problemas}

Os argumentos utilizados para sustentar as alterações pretendidas têm como base a função social da empresa, e o objetivo de evitar fiscalizações abusivas, que denotam uma inversão de valores por parte da Administração Pública. A empresa, portanto, deve ser protegida, para que o empresário possa desempenhar suas atividades com segurança jurídica e não fique à mercê da má atuação de agentes públicos.

Embora não se ignore a possível existência de abusos por agentes públicos, quando da realização de fiscalizações, é preciso destacar que as previsões trazidas pela Emenda 214/15 extrapolam a mera proteção da empresa. Seus efeitos podem causar graves prejuízos a todo um trabalho de repressão à exploração da mão-de-obra escrava, que vem sendo desenvolvido nos últimos anos, e que tem como base as fiscalizações conjuntas realizadas pelo GEFM.

Ademais, ainda que se argumente em favor da função social da empresa, é preciso ter em mente, consoante já exposto anteriormente, que a exploração de trabalho escravo atenta contra toda a sociedade, a organização do trabalho e, sobretudo, viola diretamente a dignidade das vítimas. Logo, não prospera o argumento que prioriza a proteção à empresa em detrimento da libertação das vítimas do trabalho escravo.

Em consulta recente, verificou-se que a última movimentação do Projeto de Lei $\mathrm{n}^{\circ}$ 1.572/2011, realizada em 10/11/2016, determinou a remessa do mesmo à Comissão Especial, para que seja proferido parecer acerca do substitutivo ao projeto original, que inclui diversas emendas, dentre as quais a EC 214/15.

Importante destacar que, ainda que seja rejeitada a referida emenda, a simples propositura de uma previsão tão danosa ao combate ao trabalho escravo contemporâneo já representa, por si só uma ofensa ao trabalho desenvolvido pelos grupos especiais do GEFM, que tem como principal meio de atuação a fiscalização.

\section{CONSIDERAÇÕES FINAIS}

A exploração do trabalho escravo é uma infeliz realidade, que persiste no Brasil, a despeito de todos esforços do Estado, no que tange à criação de políticas e mecanismos legais de combate. Não obstante, tem-se observado o fortalecimento de discursos retrógrados, que buscam enfraquecer a proteção, tendo como subterfúgio falso discurso da segurança jurídica.

Conforme exposto na análise acima, o fortalecimento de uma Bancada Ruralista no Congresso Nacional tem como consequência direta a eclosão de projetos de lei cujas previsões atentam diretamente contra a lógica de combate ao trabalho escravo. Os argumentos 
utilizados, consoantes restaram demonstrados, não prosperam e ignoram a produção doutrinária dos últimos anos, denotando o apego a concepções coloniais acerca do tema.

Embora o presente trabalho tenha analisado apenas projetos de lei, ou seja, documentos que podem ou não se converter em lei, é preciso destacar que a sua mera propositura já representa uma afronta não só aos órgãos e entidades que voltam suas ações para o combate ao trabalho escravo, mas, sobretudo, às vítimas do crime, que seguem tendo sua dignidade violada.

Importante destacar ainda que a dita Bancada Ruralista é composta, em sua maioria, por latifundiários e empresários do agronegócio, que reúnem em si poder econômico e político, e voltam sua atuação a temas que lhes favoreçam diretamente, sendo verdadeiros legisladores em causa própria. Isto fica evidente na medida em que se considera que, conforme notícia veiculada no site da "Revista em discussão!"8, publicada pelo Senado Federal, o agronegócio é o setor da economia que mais recruta pessoas para trabalhar em regime semelhante ao da escravidão.

Por fim, ressalta-se que o conceito de "trabalho análogo ao de escravo", previsto no artigo 149 do Código Penal, ao prever as modalidades "jornada exaustiva" e "condições de trabalho degradantes", instituiu proteção necessária, haja vista que mesmo em situações de trabalho de aparente legalidade, é possível que o mesmo seja realizado em condições semelhantes à de um escravo, em virtude do modo, intensidade e carga horária em que é realizado.

Portanto, seja por meio do encurtamento do conceito do Código Penal, seja pela instituição de um conceito mais restrito para a hipótese de expropriação de terras, ou mesmo pela modificação da lógica das fiscalizações, o que se observa é uma tendência de se reduzir a proteção às vítimas e criar mecanismos para assegurar a impunidade dos infratores, tanto no âmbito administrativo quanto no âmbito penal. Esse tipo de mitigação imprópria precisa ser combatida, visto que não é possível alcançar o futuro sem se libertar das práticas do passado.

\section{REFERÊNCIAS}

BRASIL. Constituição (1988). Constituição da República Federativa do Brasil. Aprovada em 5 de outubro de 1988. Atualizada até a Emenda Constitucional $\mathrm{n}^{\circ}$. 90, de 15.09.2015.[Texto compilado, contendo: Emendas Constitucionais, Emendas Constitucionais de Revisão, Principais Ações no STF, Ato das Disposições Constitucionais Transitórias e Índice Temático]. Disponível em:

<http://www.planalto.gov.br/ccivil_03/Constituicao/ConstituicaoCompilado.htm>. Acesso em 10.05.2017.

Decreto n. 41. 721, de 25 de junho de 1957. Promulga as Convenções Internacionais do Trabalho de $\mathrm{n}^{\mathrm{o}} 11,12,13,14,19,26,29,81,88,89,95,99,100$ e 101, firmadas pelo Brasil e outros países em sessões da Conferência Geral da Organização Internacional do Trabalho. Publicado D.O.U. 28.06.1957. Disponível em:

\footnotetext{
8 Disponível em: <https://www.senado.gov.br/noticias/Jornal/emdiscussao/trabalho-escravo/xavierplassat/trabalho-escravo-se-concentra-na-zona-rural.aspx>. Acesso em 19.05.2017.
} 
<http://www.planalto.gov.br/ccivil_03/decreto/Antigos/D41721.htm>.

Acesso

em: 10.05.2017.

Decreto-Lei n. 2.848, de 7 de dezembro de 1940. Código Penal. Publicado: D.O.U. de 31/12/1940. Disponível em:

<http://www.planalto.gov.br/ccivil_03/decreto-lei/del2848compilado.htm>. Acesso em: 25.04.2017.

Emenda Constitucional $n^{\circ}$ 81, de 05 de junho de 2014. Publicado: D.O.U. de 06/06/2014. Disponível em:

<http://www.planalto.gov.br/ccivil_03/constituicao/Emendas/Emc/emc81.htm>. Acesso em: 03/02/2016

Lei $\mathbf{n}^{\mathbf{0}}$. 3.353, de 13 de maio de 1988. Declara extinta a escravidão no Brasil. Disponível em: <http://www.planalto.gov.br/ccivil_03/leis/LIM/LIM3353.htm>. Acesso em 04.03.2016.

STF. Acordão no Inquérito 2.131/DF. Relatora: Ministra Ellen Gracie. Plenário. Publicado no DJe 23/02/2012.

STF. Acordão no RE 398.041/PA. Relator: Joaquim Barbosa. Tribunal Pleno. Publicado no DJe 30/11/2006.

BRASIL, Repórter. Dados sobre trabalho escravo no Brasil. Disponível em: <http://reporterbrasil.org.br/dados/trabalhoescravo/>. Acesso em 15.05.2017.

BRITO FILHO, José Claudio Monteiro de. Trabalho escravo: caracterização jurídica. São Paulo: LTr, 2014.

MESQUITA, Valena Jacob Chaves. O trabalho análogo ao de escravo : uma análise jurisprudencial do crime no TRF da $\mathbf{1}^{\mathbf{0}}$ Região. - Belo Horizonte : RTM, 2016.

MIRAGLIA, Lívia Mendes Moreira. Trabalho escravo contemporâneo : conceituação à luz do princípio da dignidade da pessoa humana. 2. ed. São Paulo : LTr, 2015.

NUCCI, Guilherme de Souza. Código penal comentado. 15. ed. rev., atual. e ampl.

- Rio de Janeiro: Forense, 2015.

PIOVESAN. Flávia. Trabalho Escravo e Degradante como forma de violação aos direitos humanos. In: VELLOSO, Gabriel; MARANHÃO, Ney (coord). Contemporaneidade e Trabalho - aspectos materiais e processuais. Estudos em homenagem aos 30 anos da AMATRA VIII. São Paulo: LTr, 2011. 